Pacific Journal of Mathematics

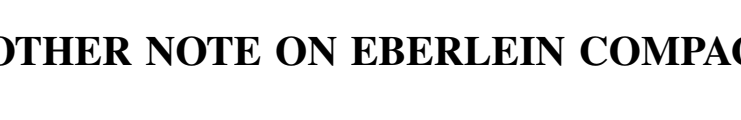




\title{
ANOTHER NOTE ON EBERLEIN COMPACTS
}

\author{
E. Michael ANd M. E. Rudin
}

An Eberlein compact is a compact space that can be embedded in a Banach space with its weak topology. It is shown that: If $X$ is compact and if $X=M_{1} \cup M_{2}$ with $M_{1}$ and $M_{2}$ metrizable, then $\bar{M}_{1} \cap \bar{M}_{2}$ is metrizable and $X$ is an Eberlein compact. This answers a question of Arhangel'skiir.

1. Introduction. An Eberlein compact, or EC, is a compact space $^{1)}$ which can be embedded in a Banach space with its weak topology. For background and various properties of these spaces, the reader is referred to [1] or the authors' preceding note [3].

Since every metrizable space can be embedded in a Banach space with its norm topology, every metrizable compact space is clearly an $E C$. The purpose of this note is to prove the following stronger result, thereby answering a question of A. V. Arhangel'skil.

THEOREM 1.1. If $X$ is compact, and if $X=M_{1} \cup M_{2}$ with $M_{1}$ and $M_{2}$ metrizable, then $\bar{M}_{1} \cap \bar{M}_{2}$ is metrizable and $X$ is an EC.

In contrast to Theorem 1.1, a compact space which is the union of three metrizable subsets need not be an $E C$, or even a Fréchet space $\left.^{2)}(\text { see [2, Example 6.2 }]^{3)}\right)$. However, it was shown in [5] that a compact space which is the union of countably many metrizable subsets must at least be sequential (a property somewhat weaker than being a Fréchet space).

2. Proof of Theorem 1.1. We first show that $M=\bar{M}_{1} \cap \bar{M}_{2}$ is metrizable. For $i=1,2$, let $\mathscr{U}_{i}$ be a $\sigma$-discrete-hence $\sigma$-disjointbase for $M_{i}$. For each $U \in \mathscr{U}_{i}$, choose an open set $\phi_{i}(U)$ in $X$ such that $\phi_{i}(U) \cap M_{i}=U$. Let $\mathscr{\mathscr { C }}=\left\{\phi_{i}(U) \cap M: U \in \mathscr{W}_{i}, i=1,2\right\}$. Then $\mathscr{U}$ is easily seen to be a $\sigma$-disjoint $1-m$ hence point-countable $1-m$ base for $M$. Since $M$ is compact, it must therefore be metrizable by a result of A. S. Miščenko [4].

Since $M$ is compact and metrizable, it has a countable base $\left(B_{n}\right)$. For each pair $(m, n)$ such that $\bar{B}_{m} \cap \bar{B}_{n}=\varnothing$, pick an open $F_{\sigma}$-set

1 All spaces in this paper are Hausdorff.

${ }^{2} X$ is a Fréchet space if, whenever $x \in \bar{A}$ in $X$, then $x_{n} \rightarrow x$ for some $x_{n} \in A$. Every $E C$ is a Fréchet space by a theorem of Eberlein and Šmulian (see [1, Theorem 4.1]).

${ }^{3}$ In this example, the three metrizable subsets are actually discrete, and one of them is an open set whose complement is (necessarily, by Theorem 1.1) an $E C$. 
$V_{m, n}$ in $X$ such that $B_{m} \subset V_{m, n}$ and $V_{m, n} \cap B_{n}=\varnothing$. Let $\mathscr{O}$ be collection of all such $V_{m, n}$.

Let $Y=X-M$. Then $Y$ is the union of the two disjoint, open metrizable subsets $X-\bar{M}_{1}$ and $X-\bar{M}_{2}$, so $Y$ is metrizable. Since $Y$ is open in $X$, it therefore has a $\sigma$-disjoint base $\mathscr{W}$ such that $\bar{W} \subset Y$ for all $W \in \mathscr{W}$. Clearly each $W \in \mathscr{W}$ is an open $F_{\sigma}$ in $X$.

Finally, let $\mathscr{S}=\mathscr{V} \cup \mathscr{W}$. Then $\mathscr{S}$ is a $\sigma$-disjoint, separating (in the sense of [3, Definition 1.3]) cover of $X$ by open $F_{\sigma}$-sets, so $X$ is an $E C$ by a characterization of H. P. Rosenthal (see [6, Theorem 3.1] or [3, Theorem 1.4]).

\section{Concluding remarks.}

(3.1) The proof of Theorem 1.1 actually establishes the following somewhat sharper results.

(a) If $X$ is regular, and if $X=\bigcup_{n=1}^{\infty} X_{n}$ with each $X_{n}$ having a $\sigma$-disjoint base, then $\bigcap_{n=1}^{\infty} \bar{X}_{n}$ has a $\sigma$-disjoint base.

(b) If $X$ is compact, and if $X=\bigcup_{n=1}^{\infty} X_{n}$ with each $X_{n}$ metrizable, then $\bigcap_{n=1}^{\infty} \bar{X}_{n}$ is metrizable.

(c) If $X$ is compact, and $X=X_{1} \cup X_{2}$ with $X_{1}$ and $X_{2}$ having $\sigma$-disjoint bases, then $X$ has a $\sigma$-disjoint, separating collection of open $F_{\sigma}$-subsets.

Observe that not every $E C$ staisfies the conclusion of (c), as can be seen from the space of all points in $\{0,1\}^{\omega_{1}}$ which have at most two nonzero coordinates.

(3.2). Somewhat in the spirit of Theorem 1.1, one can show that if $X=\bigcup_{i=1}^{n} X_{i}$, and if each $X_{i}$ is an $E C$, then $X$ is an $E C$ : In fact, $X$ is then the image under the obvious perfect map of the topological sum $\sum_{i=1}^{n} X_{i}$, and this sum is clearly an $E C$, so $X$ must be an $E C$ by [1, Theorem 2.1] (see also [3, Theorem 1.1]).

\section{REFERENCES}

1. Y. Benyamini, M. E. Rudin and M. Wage, Continuous images of weakly compact subsets of Banach spaces, to appear in Pacific J. Math.

2. S. P. Franklin, Spaces in which sequences suffice. II, Fund. Math., 61 (1967), 51-56.

3. E. Michael and M. E. Rudin, $A$ note on Eberlein compacts, Pacific J. Math., 73 (1977), 487-495.

4. A. S. Miščenko, Spaces with pointwise denumerable basis, Dokl. Akad. Nauk SSSR, 145 (1962), 985-988. (Soviet Math. Dokl. 3 (1962), 855-858.)

5. A. Ostaszewski, Compact $\sigma$-metric spaces are sequential, Proc. Amer. Math. Soc. (to appear.)

6. H. P. Rosenthal, The heredity problem for weakly compactly generated Banach spaces, Compositio Math., 81 (1974), 83-111. 
Received May 20, 1977. The second author was partly supported by N. S. F. grant MPS-73-08825.

\section{UNIVERSITY OF WASHINGTON}

Seattle, WA 98195

AND

UNIVERSITY OF WISCONSIN

MADISON, WI 53706 



\title{
PACIFIC JOURNAL OF MATHEMATICS
}

\section{EDITORS}

\author{
RICHARD ARENS (Managing Editor) \\ University of California \\ Los Angeles, CA 90024 \\ Charles W. Curtis \\ University of Oregon \\ Eugene, OR 97403 \\ C. C. MOORE \\ University of California \\ Berkeley, CA 94720
}

\section{J. DUGUNDJI}

Department of Mathematics

University of Southern California

Los Angeles, CA 90007

R. FINN and J. MILGRAM

Stanford University

Stanford, CA 94305

\section{ASSOCIATE EDITORS}
E. F. BECKENBACH
B. H. NeumanN
F. WOLF
K. YoSHIDA

\section{SUPPORTING INSTITUTIONS}

UNIVERSITY OF BRITISH COLUMBIA

CALIFORNIA INSTITUTE OF TECHNOLOGY

UNIVERSITY OF CALIFORNIA

MONTANA STATE UNIVERSITY

UNIVERSITY OF NEVADA, RENO

NEW MEXICO STATE UNIVERSITY

OREGON STATE UNIVERSITY

UNIVERSITY OF OREGON

OSAKA UNIVERSITY

\author{
UNIVERSITY OF SOUTHERN CALIFORNIA \\ STANFORD UNIVERSITY \\ UNIVERSITY OF HAWAII \\ UNIVERSITY OF TOKYO \\ UNIVERSITY OF UTAH \\ WASHINGTON STATE UNIVERSITY \\ UNIVERSITY OF WASHINGTON \\ $\stackrel{*}{*} \stackrel{*}{*} \stackrel{*}{*}$ AMERICAN MATHEMATICAL SOCIETY
}

The Supporting Institutions listed above contribute to the cost of publication of this Journal, but they are not owners or publishers and have no responsibility for its content or policies.

Mathematical papers intended for publication in the Pacific Jaurnal of Mathematics should be in typed form or offset-reproduced, (not dittoed), double spaced with large margins. Please do not use built up fractions in the text of your manuscript. You may however, use them in the displayed equations. Underline Greek letters in red, German in green, and script in blue. The first paragraph or two must be capable of being used separately as a synopsis of the entire paper. Items of the bibliography should not be cited there unless absolutely necessary, in which case they must be identified by author and Journal, rather than by item number. Manuscripts, in triplicate, may be sent to any one of the editors. Please classify according to the scheme of Math. Reviews, Index to Vol. 39. All other communications should be addressed to the managing editor, or Elaine Barth, University of California, Los Angeles, California, 90024.

The Pacific Journal of Mathematics expects the author's institution to pay page charges, and reserves the right to delay publication for nonpayment of charges in case of financial emergency.

100 reprints are provided free for each article, only if page charges have been substantially paid. Additional copies may be obtained at cost in multiples of 50 .

The Pacific Journal of Mathematics is issued monthly as of January 1966. Regular subscription rate: $\$ 7200$ a year (6 Vols., 12 issues). Special rate: $\$ 36.00$ a year to individual members of supporting institutions.

Subscriptions, orders for back numbers, and changes of address should be sent to Pacific Journal of Mathematics, 103 Highland Boulevard, Berkeley, California, 94708.

PUBLISHED BY PACIFIC JOURNAL OF MATHEMATICS, A NON-PROFIT CORPORATION

Printed at Kokusai Bunken Insatsusha (International Academic Printing Co., Ltd.). 8-8, 3-chome, Takadanobaba, Shinjuku-ku, Tokyo 160, Japan.

Copyright (C) 1975 by Pacific Journal of Mathematics Manufactured and first issued in Japan 


\section{Pacific Journal of Mathematics}

Vol. 72, No. 2

February, 1977

George E. Andrews, Plane partitions. II. The equivalence of the

Bender-Knuth and MacMahon conjectures ................. 283

Lee Wilson Badger, An Ehrenfeucht game for the multivariable quantifiers

of Malitz and some applications ......................... 293

Wayne C. Bell, A decomposition of additive set functions ............ 305

Bruce Blackadar, Infinite tensor products of $C^{*}$-algebras ............. 313

Arne Brøndsted, The inner aperture of a convex set .............. 335

N. Burgoyne, Finite groups with Chevalley-type components........... 341

Richard Dowell Byrd, Justin Thomas Lloyd and Roberto A. Mena, On the retractability of some one-relator groups .....................

Paul Robert Chernoff, Schrödinger and Dirac operators with singular potentials and hyperbolic equations .................... 361

John J. F. Fournier, Sharpness in Young's inequality for convolution ....... 383

Stanley Phillip Franklin and Barbara V. Smith Thomas, On the metrizability

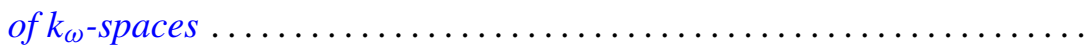

David Andrew Gay, Andrew McDaniel and William Yslas Vélez, Partially normal radical extensions of the rationals .................... 403

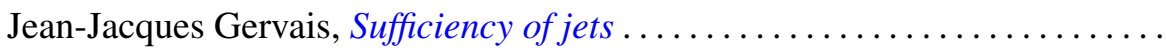

Kenneth R. Goodearl, Completions of regular rings. II . .

Sarah J. Gottlieb, Algebraic automorphisms of algebraic groups with stable maximal tori

Donald Gordon James, Invariant submodules of unimodular Hermitian forms.....

J. Kyle, $W_{\delta}(T)$ is convex.

Ernest A. Michael and Mary Ellen Rudin, A note on Eberlein compacts ...

Ernest A. Michael and Mary Ellen Rudin, Another note on Eberlein compacts ....

Thomas Bourque Muenzenberger and Raymond Earl Smithson, Fixed point theorems for acyclic and dendritic spaces.

Budh Singh Nashier and A. R. Rajwade, Determination of a unique solution of the quadratic partition for primes $p \equiv 1(\bmod 7)$.

Frederick J. Scott, New partial asymptotic stability results for nonlinear ordinary differential equations ....................

Frank Servedio, Affine open orbits, reductive isotropy groups, and dominant gradient morphisms; a theorem of Mikio Sato..........

D. Suryanarayana, On the distribution of some generalized square-full integers.................................. 